\title{
The 7-year outcome of the tension-free BJUI vaginal tape procedure for treating female stress urinary incontinence
}

\author{
Phil Hyun Song, Young Don Kim*, Hyun Tae Kim, Hwa Su Lim, Chang Ho Hyun, \\ Joon Hyung Seo ${ }^{\dagger}$, Eun Sang $\mathrm{Yoo}^{\ddagger}$, Choal Hee Park ${ }^{\star}$ and Hee Chang Jung \\ Department of Urology, College of Medicine, Yeungnam University, Daegu, ${ }^{*}$ Department of Urology, Kim Young Don \\ Urology Clinic, Daegu, ${ }^{+}$Department of Urology, Kumi CHA Medical Center, College of Medicine, Pochon Cha \\ University, Kumi, ${ }^{+}$Department of Urology, Kyungpook National University School of Medicine, Daegu, and \\ 'Department of Urology, Keimyung University School of Medicine, Daegu, Korea \\ Accepted for publication 15 January 2009
}

Study Type - Therapy (outcomes research) Level of Evidence 2c

\section{OBJECTIVE}

To evaluate the long-term results and predictive risk factors for efficacy after the tension-free vaginal tape (TVT) procedure for treating female stress urinary incontinence (SUI).

\section{PATIENTS AND METHODS}

Inall, 306 women (mean age 50.7 years, SD 8.7) who had a TVT procedure for SUI were selected and followed $\geq 7$ years (mean 92.3 months, range $84-110$ ) after surgery.
We analysed the long-term results, the variables predictive of cure rates, and patient satisfaction.

\section{RESULTS}

The overall 7-year cure rate was $84.6 \%$, with a satisfaction rate of $69.3 \%$. The cure rates were lower in patients with high-grade SUI (50\% in grade III, $82.8 \%$ in grade II and $90.7 \%$ in grade $\left.{ }_{;} P<0.001\right)$. On multivariate analysis, there were no independent risk factors related to cure rate, and urgency was the only factor independently associated with patient satisfaction ( $P=0.008$; odds ratio 2.47$)$. Seventy-one patients (23.2\%) had complications at the 1-month follow-up after surgery, but only eight (2.6\%) had complications at the 7-year follow-up, including mesh exposure in six and de novo urgency in two.

\section{CONCLUSION}

The absence of long-term adverse events associated with the TVT procedure, and high subjective and objective 7-year success rates with no independent predictive factors affecting the long-term cure rate, make the $\mathrm{TVT}$ procedure a recommendable surgical treatment for female SUI.

\section{KEYWORDS}

stress urinary incontinence, outcome, tension-free vaginal tape

\section{INTRODUCTION}

A mid-urethral tension-free sling procedure recreates the suburethral floor under the midurethra, and this enables coaptation of the urethra during increased intra-abdominal pressure; this procedure has become popular in recent years for treating stress urinary incontinence (SUI). The tension-free vaginal tape (TVT) procedure, based on the integral theory [1], was the first mid-urethral tape procedure for treating female SUI. Since evidence of efficacy was published the TVT procedure has been widely adopted before its long-term effectiveness and safety were known. However, only long-term results can establish the safety, efficacy and durability of the method, and long-term follow-up data are currently sparse [2]. In the present retrospective multicentre study in a selected homogeneous population, we evaluated the long-term ( $\geq 7$ years) results of the TVT procedure, including the long-term complication rates and predictive risk factors for the efficacy after the TVT procedure for treating female SUI.

\section{PATIENTS AND METHODS}

Between March 1999 and March 2001, 364 consecutive women complaining of SUI had a TVT procedure in three institutions in Korea. Patients excluded were those with neurological disease, known bleeding diathesis or current anticoagulant therapy, and allergy to local anaesthetic. Of 364 patients, 306 (mean age 50.7 years, SD 8.7) were followed for $\geq 7$ years (mean
92.3 months, range $84-110)$. The remaining 58 patients were lost to follow-up because they did not respond when contacted by mail and telephone. The 306 patients visited the clinic at 1 month and 1 and 7 years after surgery.

The preoperative evaluations included a medical history, obstetric history, physical examination including a 0 -tip test and stress test, a 3-day voiding diary, a 1-h pad test, uroflowmetry, a measurement of postvoid residual volume (PVR) and a multichannel urodynamic investigation conducted according to ICS standards [3]. The analysis of urodynamic variables included the peak flow rate, maximum cystometric capacity, maximum detrusor pressure, and Valsalva leak point pressure (VLPP). 
The TVT procedure was performed by experienced surgeons using the standard technique, with some modifications. Surgery was normally carried out under a combination of light sedation and local anaesthesia, but general or spinal anaesthesia was used when requested by the patients or when there were concomitant pelvic or vaginal procedures.

All patients were asked to visit the clinic at 7 years after surgery, when they were evaluated with a careful symptom review, stress test, patient overall satisfaction questionnaire, uroflowmetry with PVR measurement, and for any complications associated with the TVT procedure. Questions about satisfaction with the procedure were completed by the patient in the clinic.

The primary outcome measure at 7 years was the cure of SUI, defined as the absence of any episodes of involuntary urine leakage during stressful activities and a stress cough test. The latter was done with the patient standing and with a full bladder. Improvement was defined subjectively as a significant reduction of urine leakage, such that it did not require further treatment [4]. All other outcomes were regarded as failures. Patient satisfaction with the treatment was rated as 'very satisfied', 'satisfied', 'so-so', and 'dissatisfied', with both 'very satisfied' and 'satisfied' scored as 'satisfied.' Urgency was defined as a sudden compelling desire to pass urine, which was difficult to defer; urge incontinence was defined as involuntary leakage accompanied by or immediately preceded by urgency [5].

We analysed the clinical and urodynamic factors to determine which pre- and intraoperative factors influenced the cure and satisfaction rates of the TVT procedure for SUI. Univariate analysis was used, with Fisher's exact and chi-square tests. To determine the predictive factors affecting the cure rates and satisfaction rates, we also used a logistic regression analysis. Normally distributed variables were compared using Student's ttest. A 5\% level of significance was used for all statistical testing and all statistical tests were two-sided.

\section{RESULTS}

In all, 364 patients with female SUI were selected and 58 were lost from the study (see above); the baseline characteristics of the 306 women are shown in Table 1. Stamey's definition [6] was used for grading the

\begin{tabular}{|c|c|c|}
\hline Variable & $\begin{array}{l}\text { Mean (range) } \\
\text { or } n(\%)\end{array}$ & $\begin{array}{l}\text { TABLE } 1 \\
\text { The characteristics of the }\end{array}$ \\
\hline Age, years & $50.7(29-76)$ & 306 patients \\
\hline Parity & $2.8(0-9)$ & \\
\hline Body mass index, $\mathrm{kg} / \mathrm{m}^{2}$ & $23.7(17.4-30.5)$ & \\
\hline With cystoceles $\geq$ grade 2 & $2(0.7)$ & \\
\hline With previous anti-incontinence surgery & $5(1.6)$ & \\
\hline With urge UI & 59 (19.3) & \\
\hline With urgency & $88(28.8)$ & \\
\hline \multicolumn{3}{|l|}{ With concomitant surgery: } \\
\hline Cystocele repair & $10(3.3)$ & \\
\hline Caruncle excision & $1(0.3)$ & \\
\hline Posterior colporrhaphy & $11(3.6)$ & \\
\hline Urethral dilatation & $1(0.3)$ & \\
\hline \multicolumn{3}{|l|}{ With SUI grade } \\
\hline । & $129(42.2)$ & \\
\hline$\|$ & $163(53.3)$ & \\
\hline III & $14(4.5)$ & \\
\hline $1-h$ pad test, g & $25.7(10-82)$ & \\
\hline \multicolumn{3}{|l|}{ Urodynamic variables: } \\
\hline Peak urinary flow, $\mathrm{mL} / \mathrm{s}$ & $29.8(10-68)$ & \\
\hline Voided volume, $\mathrm{mL}$ & $309.6(24.9-790)$ & \\
\hline$P V R, m L$ & $17.2(0-77)$ & \\
\hline $\mathrm{MCC}, \mathrm{mL}$ & $425.0(171-650)$ & \\
\hline $\mathrm{MDP}, \mathrm{cmH}_{2} \mathrm{O}$ & $34.3(7-58)$ & \\
\hline VLPP, $\mathrm{cmH}_{2} \mathrm{O}$ & $66.5(32-194)$ & MCC, maximum \\
\hline $\mathrm{MUCP}, \mathrm{cmH}_{2} \mathrm{O}$ & $67.1(42-92)$ & cystometric capacity; \\
\hline $\mathrm{FBC}, \mathrm{mL}$ & $393.3(122-790)$ & MUCP, maximum urethral \\
\hline \multicolumn{3}{|r|}{ closing pressure; FBC, } \\
\hline Local & $84(27.5)$ & functional bladder \\
\hline Spinal & $173(56.5)$ & capacity; MDP, maximum \\
\hline General & 49 (16.0) & detrusor pressure. \\
\hline
\end{tabular}

TABLE 2 The 1- and 7-year outcomes, as n/N (\%), of tension-free vaginal tape in patients with MUI and pure SUI

\begin{tabular}{lccc} 
& & \multicolumn{1}{c}{7 -year } & \\
\cline { 2 - 4 } Group & 1 Cure & Satisfaction \\
\hline MUI & $50 / 59(85)$ & $46 / 59(78)$ & $32 / 59(54)$ \\
Pure SUI & $225 / 247(91.1)$ & $213 / 247(86.2)$ & $180 / 247(72.9)$ \\
$P$ & 0.147 & 0.114 & 0.005 \\
$* P<0.01$ (between MUI and pure SUI). & &
\end{tabular}

severity of SUI; this gave grade I in 129 (42.2\%) patients, grade II in 163 (53.3\%) and grade III in 14 (4.5\%). Five (1.6\%) patients had previously had surgery for UI, including Raz procedures, anterior vaginal wall slings, or bladder neck suspensions. Of the 306 women, 59 (19.3\%) complained of concomitant urge $\mathrm{UI}$ and 88 (28.8\%) of urgency. The mean (range) duration of surgery was 33.1 (20-110) $\mathrm{min}$, the duration of hospitalization was 2.8 (1-8) days and the duration of urethral catheterization was $1.1(0-5)$ days.
Overall, 259 (84.6\%) women were cured and 44 (14.4\%) were improved; 212 (69.3\%) were satisfied with the operation. The overall cure rates for pure SUI and mixed UI (MUI) were $86.2 \%$ and $78.0 \%$, respectively $(P=0.114)$.

The overall satisfaction rate was significantly higher in the group of women with the pure SUI than in those with MUI (72.9\% vs 54.2\%, respectively, $P=0.005$; Table 2 ).

Univariate analysis of the pre- and intraoperative factors showed that symptom 


\begin{tabular}{|c|c|c|}
\hline & \multicolumn{2}{|l|}{ Odds ratio $(95 \% \mathrm{Cl}), P$} \\
\hline & Cure & Satisfaction \\
\hline$\overline{\text { Age }}$ & $1.27(0.66-2.43), 0.474$ & $1.25(0.75-2.09), 0.394$ \\
\hline Parity & $1.03(0.52-2.02), 0.936$ & $1.08(0.64-1.82), 0.786$ \\
\hline Body mass index & $1.22(0.62-2.38), 0.565$ & $1.37(0.81-2.32), 0.240$ \\
\hline Menopause & $1.09(0.59-2.04), 0.721$ & 1.62 (0.99-2.63), 0.054 \\
\hline Previous hysterectomy & $0.87(0.29-2.63), 0.806$ & 0.85 (0.36-1.99), 0.701 \\
\hline \multicolumn{3}{|l|}{ SUI } \\
\hline Grade I & 1.00 (reference) & 1.00 (reference) \\
\hline Grade II-III & $2.40(1.19-4.84), 0.012$ & $1.18(0.72-1.94), 0.510$ \\
\hline MCC & $1.44(0.22-9.41), 0.653$ & $2.33(0.49-11.1), 0.407$ \\
\hline VLPP & $10.0(0.92-111.1), 0.055$ & $4.67(0.67-3.23), 0.163$ \\
\hline Maximum flow rate & $0.82(0.42-1.61), 0.564$ & $0.80(0.48-1.33), 0.388$ \\
\hline Voided volume & $0.83(0.42-1.62), 0.579$ & $1.00(0.60-1.68), 0.982$ \\
\hline PVR & $0.51(0.06-4.01), 1.00$ & $0.18(0.02-1.44), 0.118$ \\
\hline 1-h pad test & $0.34(0.10-1.18), 0.096$ & $1.60(0.58-4.38), 0.358$ \\
\hline $\mathrm{FBC}$ & $1.09(0.38-3.10), 0.792$ & $1.36(0.60-3.05), 0.461$ \\
\hline Frequency & $1.55(0.76-3.14), 0.223$ & $2.19(1.25-3.84), 0.006$ \\
\hline Urgency & $1.19(0.61-2.33), 0.603$ & $1.91(1.13-3.21), 0.014$ \\
\hline Urge UI & 1.77 (0.87-3.62), 0.114 & $2.27(1.26-4.07), 0.005$ \\
\hline Concomitant surgery & $1.24(0.41-3.86), 0.758$ & $0.64(0.23-1.80), 0.399$ \\
\hline \multicolumn{3}{|l|}{ Anaesthesia } \\
\hline Local & 1.00 (reference) & 1.00 (reference) \\
\hline Spinal & $1.62(0.75-3.48), 0.217$ & $1.61(0.89-2.92), 0.112$ \\
\hline General & $1.03(0.35-3.04), 0.954$ & $1.55(0.71-3.39), 0.268$ \\
\hline Postop complication & $0.48(0.16-1.41), 0.174$ & $0.58(0.28-1.23), 0.152$ \\
\hline
\end{tabular}

grade was associated with the cure rate of the TVT procedure (Table 3). When divided into subgroups according to symptom grade, cure rates differed, at 91\%, 83\% and 50\% in patients with grade I, II and III symptoms, respectively $(P<0.001)$. There was no significant difference in cure rates between women with a VLPP of $<60$ and $\geq 60 \mathrm{cmH}_{2} \mathrm{O}$ (60\% vs $94 \%, P=0.055)$.

In terms of age, 97 patients (31.7\%) were aged $>55$ years and 209 (68.3\%) were $<55$ years. Overall cure rates did not differ among different age groups, at $82.5 \%$ vs $85.6 \%$, respectively $(P=0.474)$. Multivariate analysis indicated that there was no independent risk factor related to the cure rate.

Univariate analysis of factors showed that urge UI, presence of frequency and urgency were related to patient satisfaction (Table 3). Multivariate analysis indicated that urgency was the only factor independently related to patient satisfaction $(P=0.008$, odds ratio 2.45). We categorized the patients into two subgroups by the presence of urgency. By uniand multivariate analyses, there was a significantly different satisfaction between these subgroups, at $73.4 \%(160 / 218)$ of patients without urgency vs $59.1 \%$ (52/88) of

There were intraoperative complications in 19 patients (6.2\%), with bladder perforation in 18 and a massive haemorrhage in one (Table 4). None of these complications required surgical intervention. Seventy-one patients (23.2\%) had complications at the 1month follow-up after surgery; 62 (20.3\%) complained of de novo urgency and de novo urge UI, which required anticholinergic therapy, and five (1.6\%) had a bloody discharge, with inguinal and suprapubic pain. One patient is asymptomatic on observation surgery due to acute urinary retention and mesh exposure. Only eight patients (2.6\%) patients with urgency. only; the remaining four (1.3\%) had corrective

\begin{tabular}{lc} 
TABLE 4 Complications during and after surgery \\
Complication & $n(\%)$ \\
\hline During surgery: & $18(5.9)$ \\
Bladder perforation & $1(0.3)$ \\
Massive haemorrhage & \\
After surgery: & \\
1 month & $46(15.0)$ \\
De novo urgency & $16(5.2)$ \\
De novo urge UI & $3(1.0)$ \\
Bloody discharge & $2(0.7)$ \\
Acute urinary retention & $2(0.7)$ \\
Mesh exposure & $1(0.3)$ \\
Inguinal pain & $1(0.3)$ \\
Suprapubic pain & \\
1 year & $18(5.9)$ \\
De novo urgency & $8(2.6)$ \\
Mesh exposure & $2(0.7)$ \\
De novo urge UI & $1(0.3)$ \\
Inguinal pain & \\
7 years & $6(2.0)$ \\
Mesh exposure & $2(0.7)$ \\
De novo urgency &
\end{tabular}

had complications at the 7-year follow-up, including de novo urgency in two and mesh exposure in six.

\section{DISCUSSION}

SUI is a highly prevalent symptom that has been estimated to be among the most common medical problems of women [7]. Although not life-threatening, SUI can seriously impair the physical, psychological, and social well-being of the affected patient [8]. The TVT procedure has become one of the most popular techniques for treating SUI, because of its ease and effectiveness. Published series $[9,10]$ with a long follow-up show good continence rates after the TVT procedure, of 70-80\%. In the present 7-year follow-up study, 259 (84.6\%) women were cured, 44 (14.4\%) improved and 212 (69.3\%) were satisfied.

For those with MUI, the TVT procedure produces variable results; e.g. one study found that patients with MUI had a cure rate of $89 \%$ at 6 months, which was not significantly different from the overall cure rate of 91\% [11]. By contrast, another study showed that patients with SUI had a cure rate of $85 \%$ at $2-8$ years after surgery, while the cure rate of those with $\mathrm{MUI}$ tended to steadily decline to $30 \%$ at $4-8$ years after surgery [12]. 
In the present study, the cure rate at 7 years after surgery was $78.0 \%$ in patients with MUI, which was not significantly different from the cure rate of $86.2 \%$ in patients with pure SUI. This discrepancy in the results might be due to the difference in the definition of cure. We defined cure as the absence of any episodes of involuntary urine leakage during stressful activities and the stress cough test, but Holmgren et al. [12] defined cure as no UI.

In the present study, univariate analysis showed that the symptom grade of SUI was associated with the cure rate, whereas urge $\mathrm{UI}$, the presence of frequency and urgency were related to patient satisfaction. However, according to the multivariate analysis none of these variables was an independent risk factor related to the cure rate. The only independent factor related to patient satisfaction was urgency.

Several reports have found pre- and intraoperative factors that could possibly be related to cure rate of the TVT procedure. Cetinel et al. [13] suggested that age was the only statistically significant variable affecting the cure rate of $\mathrm{TVT}$, which was significantly higher in patients aged $>55$ years than in those $<55$ years $(95.9 \%$ vs $76.9 \%$, respectively). In another large multicentre study of 809 patients and assessing the longterm outcome of the TVT procedure, the success rate was influenced by the operating surgeons' experience and general anaesthesia [14]. However, the present multivariate analyses found that none of the variables, including age, affected the cure rate.

Symptoms of an overactive bladder, particularly urgency and UI, can have a major impact on quality of life [15]; urgency significantly compromises the quality of life and increases the effects of symptoms $[15,16]$. In the present study the cure rate of patients with MUI was similar to that of patients with SUI. Urgency and urge UI improved in 68\% (60/88) and 78\% (46/59) of patients, respectively. The preoperative symptom of urgency associated with SUI was the only factor that influenced patient satisfaction.

Bladder perforation is one of the most frequent complications after a TVT procedure. A recent review of reports on TVT surgery showed that the bladder perforation rate was 0.7-19\% [17]. In the present study, 18 patients had a bladder perforation, in which catheter drainage for a short period was sufficient for complete bladder healing.

Although the TVT procedure creates dynamic urethral kinking without compressing the urethra at rest [18], 2.8-14\% of patients later develop obstructive voiding symptoms [19]. According to another report, the greatest obstruction-inducing risk is the surgeon, by over-tensioning the tape [20]. In the present study, two patients $(0.7 \%)$ complained of acute urinary retention during the 1-month follow-up; this resolved within 1-2 weeks after releasing the tape. Tsivian et al. [21] reported that all of patients with urinary retention were symptom-free after partial tape removal or tape incision, and McCrery et al. [22] reported that $87 \%$ of patients achieved efficient voiding after transvaginal urethrolysis.

In terms of analysing the changes in urge UI and overactive bladder symptoms after a TVT procedure, Segal et al. [23] reported that 4.3\% and $9.1 \%$ of patients with pure SUI were found to have developed de novo urgency and de novo urge $U I$, respectively. In the present study, 46 patients (15\%) had developed de novo urgency at the 1-month follow-up, but only two (0.7\%) complained de novo urgency at the 7-year follow-up, all of which resolved by anticholinergic medication.

In conclusion, the TVT procedure has a high cure rate (84.6\%) with a long-term follow-up. There are associated complications during and after surgery, but the correction of these complications is relatively simple and causes practically no long-term morbidity. The absence of long-term adverse events and high subjective and objective 7-year success rates with no independent predictive factors for the long-term cure rate make the TVT procedure a recommendable surgical treatment for female SUI.

\section{ACKNOWLEDGEMENTS}

This research was supported by the Yeungnam University research grants in 2007.

\section{CONFLICT OF INTEREST}

None declared.

\section{REFERENCES}

1 Petros PE, Ulmsten UI. An integral theory and its method for the diagnosis and management of female urinary incontinence. Scand J Urol Nephrol Suppl 1993; 153: 1-93

2 Alexander T, Baruch M, Oded K et al. Tension-free vaginal tape procedure for the treatment of female stress urinary incontinence: long-term results. J Urol 2004; 172: 998-1000

3 Abrams P, Blaivas JG, Stanton SL, Andersen JT. The standardisation of terminology of lower urinary tract function. The International Continence Society Committee on Standardisation of Terminology. Scand J Urol Nephrol Suppl 1988; 114: 5-19

4 Stamey TA. Endoscopic suspension of the vesical neck for urinary incontinence in females. Report on 203 consecutive patients. Ann Surg 1980; 192: 465-71

5 Abrams P, Cardozo L, Fall M etal. The standardization of terminology in lower urinary tract function: report from the standardization sub-committee of the International Continence Society. Urology 2003; 61: 37-49

6 Stamey TA. Endoscopic suspension of the vesical neck for urinary incontinence. Surg Gynecol Obstet 1973; 136: 547-54

7 Bemelmans BL. Stress urinary incontinence and the future of urology. Eur Urol 2007; 51: 15-6

8 Hunskaar S, Burgio K, Clark A et al. Epidemiology of urinary and faecal incontinence and pelvic organ prolapse. In Abrams P, Cardozo L, Khoury S, Wein A eds, Incontinence, 3rd International Consultation on Incontinence. Plymouth, UK: Health Publications, 2005: 255-312

9 Doo CK, Hong B, Chung BJ et al. Fiveyear outcomes of the tension-free vaginal tape procedure for treatment of female stress urinary incontinence. Eur Urol 2006; 50: 333-8

10 Kuuva N, Nilsson CG. Long-term results of the tension-free vaginal tape operation in an unselected group of 129 stress incontinent women. Acta Obstet Gynecol Scand 2006; 85: 482-7

11 Abdel-Hady el S, Constantine G. Outcome of the use of tension-free vaginal tape in women with mixed urinary incontinence, previous failed surgery, or low Valsalva pressure. J Obstet Gynaecol Res 2005; 31: 38-42

12 Holmgren C, Nilsson S, Lanner L et al. Long-term results with tension-free vaginal tape on mixed and stress urinary incontinence. Obstet Gynecol 2005; 106: 38-43 
13 Cetinel B, Demirkesen O, Onal B et al. Are there any factors predicting the cure and complication rates of tension-free vaginal tape? Int Urogynecol J Pelvic Floor Dysfunct 2004; 15: 188-93

14 Koops SE, Bisseling TM, van Brummen $\mathrm{HJ}$ et al. What determines a successful tension-free vaginal tape? A prospective multicenter cohort study: results from The Netherlands TVT database. Am J Obstet Gynecol 2006; 194: 65-74

15 Coyne KS, Payne C, Bhattacharyya SK et al. The impact of urinary urgency and frequency on health-related quality of life in overactive bladder: results from a national community survey. Value Health 2004; 7: 455-63

16 Porena M, Costantini E, Frea B et al. Tension-free vaginal tape versus transobturator tape as surgery for stress urinary incontinence: results of a multicenter randomised trial. Eur Urol 2007; 52: 1481-91

17 Abouassaly R, Steinberg JR, Lemieux M et al. Complications of tension-free vaginal tape surgery: a multi-institutional review. BJU Int 2004; 94: 110-3

18 Lo TS, Wang AC, Horng SG, Liang CC, Soong YK. Ultrasonographic and urodynamic evaluation after tension free vagina tape procedure (TVT). Acta Obstet Gynecol Scand 2001; 80: 65-70

19 Klutke C, Siegel S, Carlin B, Paszkiewicz E, Kirkemo A, Klutke J. Urinary retention after tension-free vaginal tape procedure: incidence and treatment. Urology 2001; 58: 697-701

20 Fischer A, Fink T, Zachmann S, Fickenbusch U. Comparison of retropubic and outside-in transobturatorsling systems for the cure of female genuine stress urinary incontinence. Eur Urol 2005; 48: 799-804

21 Tsivian A, Kessler 0, Mogutin B et al. Tape related complications of the tensionfree vaginal tape procedure. J Urol 2004; 171: 762-4
22 McCrery R, Appell R. Transvaginal urethrolysis for obstruction after antiincontinence surgery. Int Urogynecol J Pelvic Floor Dysfunct 2007; 18: 627-33

23 Segal JL, Vassallo B, Kleeman S, Silva WA, Karram MM. Prevalence of persistent and de novo overactive bladder symptoms after the tension-free vaginal tape. Obstet Gynecol 2004; 104: 1263-9

Correspondence: Hee Chang Jung, Department of Urology, Yeungnam University College of Medicine, 317-1 Daemyung-dong, Nam-gu, Daegu, 705-035, Republic of Korea. e-mail: junghc@med.yu.ac.kr

Abbreviations: (S)(M)UI, (stress) (mixed) urinary incontinence; TVT, tension-free vaginal tape; PVR, postvoid residual urine volume; VLPP, Valsalva leak point pressure.

\section{EDITORIAL COMMENT}

The TVT was the first, and remains arguably the most popular, of all the mid-urethral sling procedures for SUI in women. Despite its popularity and the many reports expounding its virtues, long-term results of the TVT are only now emerging. While most current studies, such as this by Song et al., are inherently limited by their retrospective and non-randomized nature, they give us some excellent food for thought. Large-volume, multi-institutional studies with a minimum follow-up of $>7$ years are rare, and the authors are to be commended for their extensive evaluation, formidable SUI cure rates (85\%), and low rate of perioperative complications. Also, the use of not only subjective outcome measures (no SUI by history) but also objective measures (standing cough-stress test) is timely and lends support to their conclusions.

This report inspires some additional comments. The authors' argument might have been stronger had they assessed quality of life before surgery and used validated subjective outcome measures after surgery. Also, there is a 16\% loss to follow-up, and although some previously published trials have had higher rates, the outcomes in these 'non-responders' could skew the cure and satisfaction rates significantly. Furthermore, although the urinary retention and sling-release rate was very low in the study, there was a significant rate of de novo or worsened urinary storage symptoms after surgery. Some of these symptoms might possibly have been related to excess sling tension. As the role of sling incision remains unclear in the treatment of postoperative urinary storage symptoms, it was encouraging to see these symptoms resolve in the long-term follow-up.

This leads to a final thought; the true strength of this report might lie in its selected population of women with relatively 'pure' SUI. The young, thin woman with minimal concomitant preoperative urgency, urge UI and significant pelvic prolapse, and no previous anti-incontinence surgery, might be a veritable 'unicorn' for most incontinence surgeons. As such, it might be possible to glean a 'true' incidence of de novo or worsened postoperative voiding dysfunction is this group of women with other preoperative symptoms. It is not surprising then, that there is a disparity between SUI cure rate and satisfaction rate, and that this disparity is directly related to the persistence, worsening or development of urinary storage symptoms. It begs the question 'Is it better to be dry and unhappy, or be wet and happy?' At present there is no agreed answer and it is unclear if it is a worthy compromise in the long-term. Taken at face value, the findings in this longterm study might ultimately be helpful in the preoperative counselling of some of the women with more straightforward SUI.

\author{
Alexander Gomelsky, \\ Urology, LSU Health Sciences Center, \\ Shreveport, LA, USA
}

